\title{
Third generation bioethanol from invasive macroalgae Sargassum muticum using autohydrolysis pretreatment as first step of a biorefinery
}

\author{
Pablo G. del Río ${ }^{\text {a }}$, Elena Domínguez ${ }^{a}$, Viana D. Domínguez ${ }^{\text {a }}$, Aloia Romaní ${ }^{\mathrm{b}}$, \\ Lucília Domingues ${ }^{\mathrm{b}}$, Gil Garrote ${ }^{\mathrm{a}, *}$ \\ a Department of Chemical Engineering, Faculty of Science, University of Vigo (Campus Ourense), As Lagoas, 32004, Ourense, Spain \\ ${ }^{\mathrm{b}}$ CEB-Centre of Biological Engineering, University of Minho, Campus Gualtar, 4710-057, Braga, Portugal
}

\section{A R T I C L E I N F O}

\section{Article history:}

Received 4 July 2018

Received in revised form

15 February 2019

Accepted 14 March 2019

Available online 19 March 2019

\section{Keywords:}

Sargassum muticum

Invasive seaweed

Autohydrolysis

Enzymatic hydrolysis

Simultaneous saccharification and

fermentation

Industrial strains

\begin{abstract}
A B S T R A C T
Sargassum muticum, an invasive macroalgae in Europe, was employed as material for third generation bioethanol production. As a first step, autohydrolysis was chosen as an eco-friendly pretreatment, seeking for a high enzymatic susceptibility of the solid phase and high content of hexoses as glucose, galactose and mannose, in both liquid and solid phases, which can be subsequently transformed in ethanol via fermentation. Besides, the search of a minimum consumption of energy in the pretreatment is also a key challenge in bioethanol production.

At optimum conditions of autohydrolysis pretreatment, more than $90 \%$ of the glucan was recovered in the solid phase (while the other $10 \%$ appeared as glucooligosaccharides and glucose in the liquid phase). In the enzymatic hydrolysis carried out with the solid phases, glucan to glucose conversions of 94 and $89 \%$ were obtained, with the solid mixed with water and the whole slurry, respectively.

Moreover, the whole slurry experiments, where all hexoses present in the raw material (glucose, galactose and mannose) from the solid and the liquid phases are fermented, allows to reach maximum ethanol yields of $80 \%$ ( $14.10 \mathrm{~g}$ of ethanol/L) referred to the theoretical yield, in a short time.
\end{abstract}

() 2019 Elsevier Ltd. All rights reserved.

\section{Introduction}

In the last century, fossil resources were the main feedstock used to produce fuels, chemicals and all kinds of materials. Human dependence, especially of fossil fuels, have started to become a worldwide problem in the last decades. Consequently, new and sustainable energies have become a high-potential alternative, and biorefinery has stood out as an interesting way to produce them $[1,2]$.

For this purpose, sustainable feedstock has gained a lot of attention due to its low cost [3]. Seaweeds have become very popular recently, having fast growing rates, huge biomass yields and the advantage that no land is needed for cultivation. In addition, the high carbohydrate content allows them to be a suitable feedstock for the production of biofuels such as ethanol, hydrogen or butanol $[4,5]$.

\footnotetext{
* Corresponding author.

E-mail address: gil@uvigo.es (G. Garrote).
}

The seaweed Sargassum muticum was employed as raw material due to its potential in industrial applications and production of chemicals [6]. It is a brown alga originate in Japan, and mainly present in the European Atlantic waters (from the south of Portugal to the south coast of Norway) and West Coast of America, where is considered invasive. Invasive macroalgae are considered main menace to oceanic native species and resources all over the world, so many strategies are being evaluated in order to control their proliferation. However, in Europe, Sargassum muticum has a high biomass production and a high physiological tolerance towards dryness, salinity, temperature and sun exposure which made it greatly competitive, even displacing other seaweeds [7-9] so its exploitation could be an interesting solution. As far as we know, few works of bioethanol production from Sargassum have been released [10-13], but none about Sargassum muticum.

The first step to take advantage of this seaweed would be to pretreat it, and autohydrolysis is a suitable way. It consists on heating a mixture of the raw material with water at high temperature, hence the reaction is only catalyzed by hydronium ions and 
organic acids generated consequently, like acetic acid, without the addition of any other compound. Therefore, autohydrolysis is an eco-friendly pretreatment, which allows to obtain a solid phase with high enzymatic susceptibility and a liquid phase rich in oligosaccharides [14].

Saccharomyces cerevisiae has become the most employed microorganism to obtain bioethanol [15] from hexoses as glucose and galactose $[16,17]$. Thus, it is desirable to make a whole slurry fermentation, where both liquid and solid fractions are employed simultaneously, without the need to use stages of separation or detoxification. Besides, the maximum quantity of sugars can be fermented and the cost can be reduced by avoiding the separation process and/or the washing of the solid fraction [18]. However, laboratory yeast strains are not suitable for fermenting cellulosic hydrolysates containing inhibitors [19], which can be found in the liquid phase. The first solution could be to remove the inhibitors, but it would increase the cost of the process, so the employment of genetically modified or robust yeast strains isolated from industrial environments, which have shown superiority fermentation performance in presence of inhibitor compounds, can be an interesting alternative to chemical detoxification processes [20].

In this work, an invasive seaweed (Sargassum muticum) has been explored as alternative renewable resource for the production of bioethanol, following the scheme displayed in Fig. 1. An environmentally friendly treatment, using water as reaction media was used for the fractionation of Sargassum muticum. Soluble oligosaccharides and insoluble polysaccharides were identified and quantified as function of treatment of severity. Moreover, enzymatic saccharification and fermentation of whole slurry derived from the treatment was also evaluated using two industrial and one laboratory Saccharomyces cerevisiae strains.

\section{Materials and methods}

\subsection{Raw material}

The raw material employed in this study was the macroalgae Sargassum muticum (Sm), collected in Praia da Mourisca (Pontevedra, NW Spain) in August 2016. Sm was firstly frozen until use, process that is usually employed with algae [21,22] and do not alter significantly the composition and behavior of raw material [23]. Afterwards, Sm was cleaned, washed with tap water, chopped until size of particle smaller than $8 \mathrm{~mm}$, air dried and stored in plastic bags.

\subsection{Analysis of the raw material}

Samples from the lot were milled to a size smaller than $1 \mathrm{~mm}$ and analyzed (see Table 1) employing the following procedures: extractives [24], moisture [25], ashes [26], quantitative acid hydrolysis (QAH) [27] and Organic Elemental Analysis for the nitrogen content (which allows to calculate the protein content).

Two sequential extractions with: (i) water and (ii) ethanol (96\% $\mathrm{v} / \mathrm{v}$ ), were carried out in order to remove water-soluble and fatsoluble compounds, respectively. An aliquot from both of the extractions was subjected to non-volatile solid content and quantitative posthydrolysis $\left(121^{\circ} \mathrm{C}, 20 \mathrm{~min}, 4 \% \mathrm{H}_{2} \mathrm{SO}_{4}\right)$. The liquid resulting, as well as the liquid extracted were filtered through $0.45 \mu \mathrm{m}$ membranes and analyzed by high performance liquid chromatography (HPLC) to quantify the solubilized compounds, such as glucose, xylose, galactose, mannose, fucose and acetic acid. The conditions used in the HPLC analysis were as follows: (i) detector, refractive index at $35^{\circ} \mathrm{C}$; column, Aminex HPX-87H; mobile phase, $0.03 \mathrm{M} \mathrm{H}_{2} \mathrm{SO}_{4}$; flow rate, $0.6 \mathrm{~mL} / \mathrm{min}$; column temperature $50{ }^{\circ} \mathrm{C}$; and (ii) detector, refractive index at $35^{\circ} \mathrm{C}$; column, Aminex HPX-87P; mobile phase, ultrapure water; flow rate, $0.4 \mathrm{~mL} / \mathrm{min}$; column temperature, $80^{\circ} \mathrm{C}$. The concentrations resulting were added up to the raw material content.

The liquid from the QAH was analyzed by HPLC as well, using the same conditions as before. Glucan, xylan, galactan, mannan, fucoidan and acetyl groups were calculated from the concentrations of glucose, xylose, galactose, mannose, fucose and acetic acid after QAH $\left(121{ }^{\circ} \mathrm{C}, 60 \mathrm{~min}, 4 \% \mathrm{H}_{2} \mathrm{SO}_{4}\right)$. The insoluble phase from the

Table 1

Composition of Sargassum muticum.

\begin{tabular}{ll}
\hline Component & $\mathrm{g} / 100 \mathrm{~g}$ oven dried $\mathrm{Sm} \pm$ standard deviation \\
\hline Glucan & $10.18 \pm 0.23$ \\
Xylan & $1.64 \pm 0.10$ \\
Galactan & $2.69 \pm 0.11$ \\
Mannan & $2.42 \pm 0.01$ \\
Fucoidan & $6.00 \pm 0.11$ \\
Acetyl groups & $0.33 \pm 0.01$ \\
AIR (Acid Insoluble Residue) & $25.03 \pm 0.40$ \\
Water extractives & $11.34 \pm 0.09$ \\
Ethanol (96\% v/v) extractives & $2.05 \pm 0.13$ \\
Ashes & $11.87 \pm 0.22$ \\
Proteins & $10.55 \pm 0.42$ \\
Uronic acids & $19.28 \pm 0.56$ \\
\hline
\end{tabular}

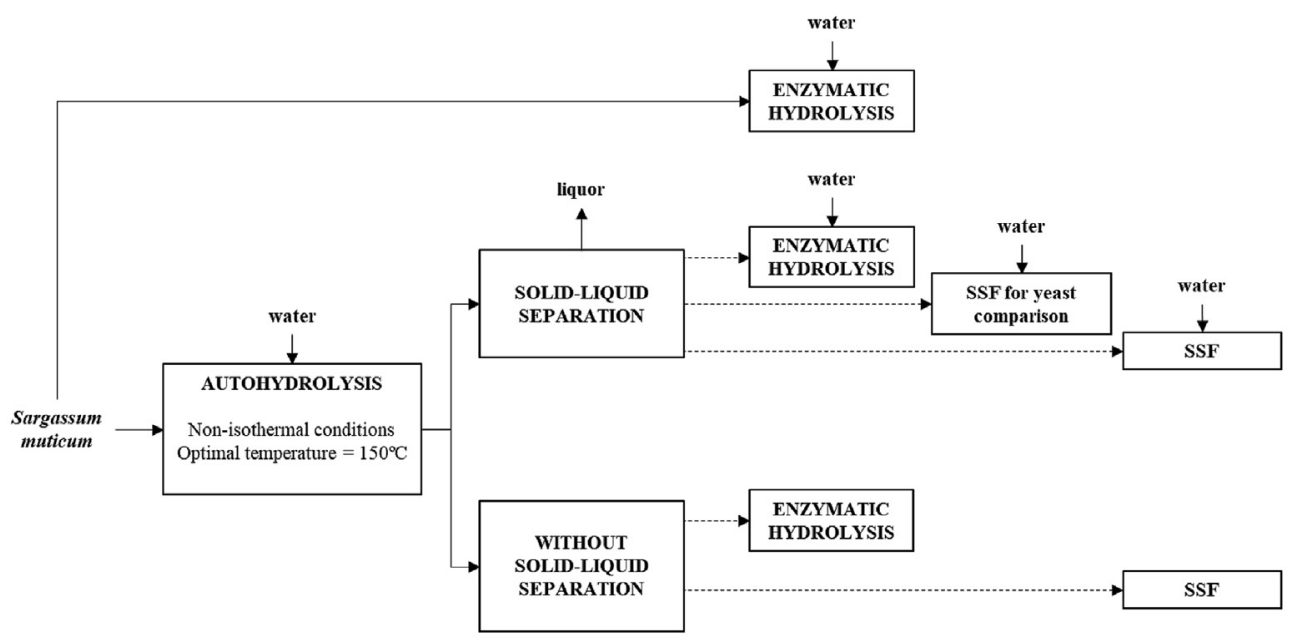

Fig. 1. Flow diagram considered in this work. 
QAH was subjected to gravimetric quantitation and reported as acid insoluble residue (AIR). Uronic acids were determined using a colorimetric method [28], and expressed as equivalents in galacturonic acid. All the analysis were carried out in triplicate.

\subsection{Non-isothermal autohydrolysis treatment}

Autohydrolysis was carried out in a pressurized stainless steel Parr reactor (Parr Instruments Company, Moline, IL) with $0.6 \mathrm{~L}$ capacity. It was heated by an external fabric mantle, cooled by flowing water through an internal loop and equipped with four blade impeller. Water and $\mathrm{Sm}$ were blended in the reactor within a consistency (C) of $14.3 \mathrm{~kg}$ of solid/100 kg of total weight, oven dry basis (o.d.b.), stirring at $150 \mathrm{rpm}$ and heated to reach the maximum temperature $\left(\mathrm{T}_{\mathrm{MAX}}\right)$ and then cooled to room temperature, following the heating and cooling profiles shown in Fig. 2.

The harshness of the pretreatment was expressed as severity $\left(\mathrm{S}_{0}\right)$, defined by the following equation [29]:

$$
\begin{aligned}
S_{0} & =\log R_{0}=\log \left(R_{0_{\text {HEATING }}}+R_{0_{\text {COOLING }}}\right) \\
& =\log \left[\int_{0}^{t M A X} \exp \left(\frac{T(t)-T_{R E F}}{\omega}\right) \cdot d t\right] \\
& +\left[\int_{t M A X}^{t F} \exp \left(\frac{T^{\prime}(t)-T_{R E F}}{\omega}\right) \cdot d t\right]
\end{aligned}
$$

where $R_{0}$ is the severity factor (min), $t_{\text {MAX }}(\min )$ is the time employed to achieve the target temperature $\mathrm{T}_{\mathrm{MAX}}\left({ }^{\circ} \mathrm{C}\right), \mathrm{t}_{\mathrm{F}}(\mathrm{min})$ is the time used for the whole heating-cooling period, and $\mathrm{T}(\mathrm{t})$ and $\mathrm{T}^{\prime}(\mathrm{t})$ represent the temperature profiles in the heating and cooling stages, respectively. Specifically, $\mathrm{T}(\mathrm{t})$ and $\mathrm{T}^{\prime}(\mathrm{t})$ represent the variation of dependent variable Temperature $(\mathrm{T})$ with the independent variable time $(t)$. There is no equation to represent this variation of $\mathrm{T}$ with $\mathrm{t}$ so, instead, the temperature profile of heating and cooling stages was recorded in each experiment, as a set of (temperature, time) points. These two set of points were used for the numerical resolution of the two integrals, using the Simpon's Rule. Calculations were made using the values $14.75^{\circ} \mathrm{C}$ and $100^{\circ} \mathrm{C}$ for $\omega$ and $\mathrm{T}_{\mathrm{REF}}$.

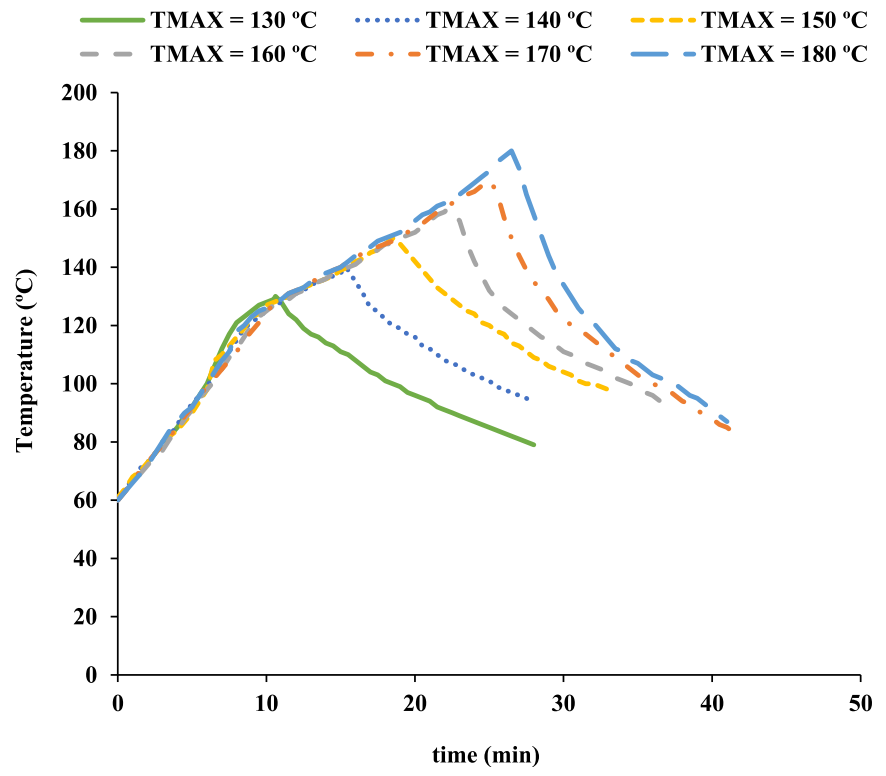

A wide range of temperatures $\left(130-180^{\circ} \mathrm{C}\right.$, corresponding to $S_{0}$ from 1.69 to 3.06) were studied in order to get an overall view of the effect of the pretreatment and maximize the glucan content in the solid phase, improving its enzymatic susceptibility, while maintaining a high content in other hexoses (galactose, mannose) which can be fermentable.

When room temperature is reached, liquid and solid phases were separated by centrifugation. Solid phase was washed, air dried and employing for the quantification of the solid yield (SY, g solid recovered/100 g raw material, o.d.b.). An aliquot of the solid phase was analyzed for chemical composition via QAH described above (section 2.2). Two aliquots of the liquid phase were subjected to: (i) filtration through $0.45 \mu \mathrm{m}$ membranes and analysis in HPLC for glucose, xylose, galactose, mannose, fucose, formic acid, acetic acid, hydroxymethylfurfural (HMF) and furfural (F) quantitation, (ii) quantitative acid posthydrolysis, filtration through $0.45 \mu \mathrm{m}$ membranes and quantification of oligosaccharides in HPLC. All the analysis were carried out in triplicate.

\subsection{Enzymatic susceptibility}

After the pretreatment step, enzymatic hydrolysis (EH) experiments were carried out in order to evaluate the enzymatic susceptibility of the solid and liquid phases. Thus, three type of experiments of enzymatic hydrolysis were performed: (i) raw Sm mixed with water, (ii) autohydrolyzed Sm mixed with water, (iii) whole slurry from autohydrolysis of Sm, including both liquid and solid phases (without separation).

They were performed at $48.5^{\circ} \mathrm{C}$ in an orbital agitator $(150 \mathrm{rpm})$ and $\mathrm{pH} 4.85$ (using $0.05 \mathrm{~N}$ citric acid-sodium citrate buffer). In the whole slurry experiment, solid from autohydrolysis was not washed with water in order to maintain the liquor phase within the solid phase, while in the experiment with autohydrolyzed Sm at $150{ }^{\circ} \mathrm{C}$ and water, the solid phase was washed in order to remove the liquor from the solid phase. Same procedure was used for the subsequent SSF (section 2.6.).

Commercial enzymes provided by Novozymes (Madrid, Spain) were utilized: "Celluclast $1.5 \mathrm{~L}$ " cellulases from Trichoderma reesei, "Novozyme 188" $\beta$-glucosidase from Aspergillus niger and "Viscozyme $1.5 \mathrm{~L}^{\prime \prime}$ carbohydrases and pectinases from Aspergillus aculeatus. Cellulase activity was reported following the Filter Paper assay [30], and expressed in terms of Filter Paper Units (FPU). The $\beta$ glucosidase (cellobiase) activity of "Novozyme 188" was measured in International Units (IU) [31]. The polygalacturonase activity for Viscozyme 1.5L was measured by the amount of D-galacturonic acid formation from $0.5 \% \mathrm{w} / \mathrm{v}$ polygalacturonic acid in $50 \mathrm{mM}$ sodium acetate buffer ( $\mathrm{pH} 5$ ) following the DNS method. The amount of enzyme which catalyzes the formation of D-galacturonic acid per minute at $\mathrm{pH} 5$ and $37^{\circ} \mathrm{C}$ defines the unit of enzymatic activity (U). The mixture of enzymes had a synergistic effect and allow to yield higher monosaccharides content than using only one [32]. The enzyme activities for Celluclast 1.5L, Novozyme 188 and Viscozyme 1.5L were $70 \mathrm{FPU} / \mathrm{mL}, 630 \mathrm{IU} / \mathrm{mL}$ and $4206 \mathrm{U} / \mathrm{mL}$ respectively.

At preset times, samples were withdrawn, centrifuged at $5000 \mathrm{rpm}$ for $10 \mathrm{~min}$, and filtered through $0.45 \mu \mathrm{m}$ membranes to HPLC analysis for glucose concentration.

The results of $\mathrm{EH}$ can be expressed in terms of glucose concentrations $(\mathrm{g} / \mathrm{L})$ or in terms of glucan to glucose conversion (GC) (\%) calculated using the expression (the dimensional analysis of this equation is shown as Supplementary Information):

$$
G C=100 \cdot \frac{G_{t}-G_{t=0}}{\frac{G n}{100} \cdot \frac{180}{162} \cdot \frac{\rho}{\frac{100}{C}-\frac{A R R}{100}}}
$$

Fig. 2. Heating and cooling profiles of autohydrolysis. 
where $G_{t}$ is the glucose concentration $(g / L)$ achieved at time $t$ and $G_{t=0}$ is the glucose concentration at the beginning of the experiments. The denominator of this fraction represents the potential glucose concentration (corresponding to total conversion of the substrates into glucose) where, $\mathrm{Gn}$ is the glucan content of pretreated biomass (g glucan/100 g of autohydrolyzed Sm, o.d.b., see Table 1), 180/162 is the stoichiometric factor for glucan hydration upon hydrolysis (which represents the molecular weights for glucose in monomeric and polymeric forms, respectively), $\rho$ is the density of the reaction medium (with an average value of $1005 \mathrm{~g} / \mathrm{L}$ ), $\mathrm{C}$ is the consistency ( $\mathrm{g}$ solid/100 $\mathrm{g}$ of total weight) and AIR is the Acid Insoluble Residue content of pretreated biomass (g AIR/100 g of pretreated Sm, o.d.b., see Table 2). For the whole slurry experiments, not only Gn from the solid phase is quantified but also GO (glucooligosaccharides) from the liquid phase, so the GO content is multiplied by the stoichiometric factor $180 / 162$ and added to the potential glucose concentration.

Data from enzymatic hydrolysis experiments can be fitted to empirical model described by Holtzapple [33] as follows:

$G C_{t}=G C_{M A X} \cdot \frac{t}{t+t_{1 / 2}}$

where $\mathrm{GC}_{\mathrm{MAX}}$ and $\mathrm{t}_{1 / 2}$ are fitting parameters measuring the maximum glucose conversion (\%) achievable at infinite reaction time, and $t_{1 / 2}(h)$ measures the reaction time needed to reach a glucose conversion corresponding to $50 \%$ of $\mathrm{GC}_{\mathrm{MAX}}$.

\subsection{Yeast strains and inoculum preparation}

Three different Saccharomyces cerevisiae strains (two industrial strains: Ethanol Red ${ }^{\circledR}$ and PE2; and a laboratory strain CEN.PK 1137D) were used for the fermentation assays.

The stock cultures were kept on YPD (1\% (w/v) of yeast extract, $2 \%(\mathrm{w} / \mathrm{v})$ of bacto-pectone and $2 \%(\mathrm{w} / \mathrm{v})$ of glucose) agar at $4{ }^{\circ} \mathrm{C}$. In the inoculation step, yeast strains were grown in erlenmeyer flasks containing $10 \mathrm{~g}$ yeast extract/L, $20 \mathrm{~g}$ peptone/L, and $20 \mathrm{~g}$ glucose/L for $15 \mathrm{~h}$ at $30^{\circ} \mathrm{C}$. Inoculum media were centrifuged for $10 \mathrm{~min}$ at $4000 \mathrm{rpm}$ and $4{ }^{\circ} \mathrm{C}$ in order to collect the cells which were resuspended in $0.9 \% \mathrm{NaCl}$ to a concentration of $200 \mathrm{~g}$ fresh yeast/L. Experiments were inoculated with $8 \mathrm{~g}$ of this suspension/L (corresponding to $1.8 \mathrm{~g}$ dry cell/L).

\subsection{Simultaneous saccharification and fermentation (SSF)}

Autohydrolyzed solids were employed in SSF assays, using two different liquid phases: water and liquor resulted from autohydrolysis treatment (whole slurry). SSF experiments were carried out in an orbital incubator at consistencies of 14.3 and $11.1 \mathrm{~kg}$ of solid $/ 100 \mathrm{~kg}$ of total weight, o.d.b., at $35^{\circ} \mathrm{C}, \mathrm{pH}=5$ and $150 \mathrm{rpm}$. The enzymes (CellicCTec2, Viscozyme) used in this work were kindly supplied by Novozymes (Denmark). Cellulase activity of CellicCtec2 was measured by de Filter Paper Assay (explained in section 2.5.) and the value was $123 \mathrm{FPU} / \mathrm{mL}$. SSF assays were carried out at enzyme loading of $20 \mathrm{FPU} / \mathrm{g}$ for CellicCTec2, Viscozyme/ CellicCTec2 ratio of $5 \mathrm{U} / \mathrm{FPU}$. The experiments were performed without the addition of commercial supplementation (peptone and yeast extract) or any other kind of nutrients, due to the high content of protein of Sm, which provides a great quantity of nitrogen in order to diminish the cost of the process.

Samples were withdrawn at desired times, centrifuged at $5000 \mathrm{rpm}$ for $10 \mathrm{~min}$, filtered through $0.2 \mu \mathrm{m}$ membranes and analyzed via HPLC for sugars (glucose, galactose + mannose) and ethanol concentration.

The results of the SSF can be expressed in terms of ethanol yield (\%) using the following equation:

\%ethanol yield $=\frac{[\text { EtOH }]_{f}-[\text { EtOH }]_{0}}{0.51(f[\text { Biomass }] 1.111)} \cdot 100 \%$

where $[\mathrm{EtOH}]_{\mathrm{f}}$ is the ethanol concentration at the end of the fermentation $(\mathrm{g} / \mathrm{L}),[\mathrm{EtOH}]_{0}$ is the ethanol concentration at the beginning of the fermentation $(\mathrm{g} / \mathrm{L})$, [Biomass] is the dry biomass concentration at the beginning of the fermentation $(\mathrm{g} / \mathrm{L}), \mathrm{f}$ is the $\mathrm{C} 6$ polysaccharides (glucan, galactan and mannan) fraction of biomass $(\mathrm{g} / \mathrm{g}), 0.51$ is conversion factor for C6 hexoses (glucose, galactose and mannose) to ethanol based on stoichiometric biochemistry of

Table 2

Data of autohydrolysis processing of Sargassum muticum: solid yield and composition of solid and liquid phases.

\begin{tabular}{|c|c|c|c|c|c|c|}
\hline $\mathrm{T} \max \left({ }^{\circ} \mathrm{C}\right)$ & 130 & 140 & 150 & 160 & 170 & 180 \\
\hline $\mathrm{S}_{0}$ (dimensionless) & 1.69 & 2.02 & 2.34 & 2.59 & 2.84 & 3.06 \\
\hline SY (\% of solid recovered) & $89.29 \%$ & $87.55 \%$ & $81.67 \%$ & $75.73 \%$ & $65.11 \%$ & $66.72 \%$ \\
\hline \multicolumn{7}{|l|}{$\begin{array}{l}\text { Solid phase composition } \\
\text { (g/100 g autohydrolyzed Sm, o.d.b.) }\end{array}$} \\
\hline Gn (Glucan) & $7.88 \pm 0.88$ & $10.38 \pm 0.35$ & $12.46 \pm 0.83$ & $12.83 \pm 0.12$ & $14.91 \pm 0.03$ & $12.73 \pm 0.21$ \\
\hline Xn (Xylan) & $0.81 \pm 0.11$ & $0.88 \pm 0.04$ & $0.90 \pm 0.05$ & $0.61 \pm 0.10$ & $0.46 \pm 0.04$ & $0.24 \pm 0.11$ \\
\hline Gan + Man (Galactan + Mannan) & $4.14 \pm 0.34$ & $2.92 \pm 0.05$ & $2.91 \pm 0.37$ & $2.61 \pm 0.09$ & $1.80 \pm 0.04$ & $1.98 \pm 0.11$ \\
\hline Fun (Fucoidan) & $6.14 \pm 0.05$ & $3.68 \pm 0.05$ & $3.26 \pm 0.02$ & $2.54 \pm 0.04$ & $1.46 \pm 0.05$ & $2.88 \pm 0.07$ \\
\hline AcG (Acetyl groups) & $0.13 \pm 0.05$ & $0.07 \pm 0.01$ & $0.11 \pm 0.06$ & $0.05 \pm 0.01$ & $0.07 \pm 0.02$ & $0.06 \pm 0.02$ \\
\hline AIR (Acid Insoluble Residue) & $25.09 \pm 0.17$ & $36.19 \pm 0.25$ & $35.62 \pm 0.18$ & $40.56 \pm 0.69$ & $49.68 \pm 0.19$ & $50.91 \pm 0.63$ \\
\hline \multicolumn{7}{|l|}{ Liquid phase composition (g/L) } \\
\hline G (Glucose) & 0.10 & 0.15 & 0.02 & 0.07 & 0.08 & 0.05 \\
\hline X (Xylose) & 0.00 & 0.00 & 0.00 & 0.02 & 0.03 & 0.06 \\
\hline $\mathrm{Ga}+\mathrm{Ma}$ (Galactose + Mannose) & 0.06 & 0.06 & 0.08 & 0.06 & 0.19 & 0.50 \\
\hline Fu (Fucose) & 0.07 & 0.15 & 0.37 & 0.83 & 1.38 & 1.76 \\
\hline Fo (Formic acid) & 0.15 & 0.19 & 0.24 & 0.48 & 1.28 & 2.54 \\
\hline AcH (Acetic acid) & 0.07 & 0.08 & 0.31 & 0.31 & 0.40 & 0.51 \\
\hline HMF (Hydroxymethylfurfural) & 0.00 & 0.00 & 0.00 & 0.00 & 0.00 & 0.00 \\
\hline F (Furfural) & 0.00 & 0.00 & 0.00 & 0.00 & 0.00 & 0.00 \\
\hline GO (Glucooligosaccharides) & $2.04 \pm 0.04$ & $2.58 \pm 0.03$ & $1.26 \pm 0.02$ & $0.99 \pm 0.01$ & $0.96 \pm 0.01$ & $1.12 \pm 0.03$ \\
\hline XO (Xylooligosaccharides) & $0.32 \pm 0.02$ & $0.73 \pm 0.11$ & $1.55 \pm 0.11$ & $1.84 \pm 0.07$ & $1.73 \pm 0.04$ & $1.41 \pm 0.01$ \\
\hline $\begin{array}{l}\mathrm{GaO}+\mathrm{MaO} \text { (Galactooligosaccharides + } \\
\quad \text { Mannoligosaccharides) }\end{array}$ & $3.05 \pm 0.03$ & $3.67 \pm 0.13$ & $2.41 \pm 0.10$ & $2.98 \pm 0.13$ & $4.78 \pm 0.18$ & $4.37 \pm 0.13$ \\
\hline FuO (Fructooligosaccharides) & $5.97 \pm 0.03$ & $7.25 \pm 0.07$ & $9.85 \pm 0.13$ & $10.21 \pm 0.06$ & $9.56 \pm 0.20$ & $7.98 \pm 0.23$ \\
\hline AcO (Acetyl groups linked to oligosaccharides) & $0.33 \pm 0.00$ & $0.33 \pm 0.02$ & $0.15 \pm 0.02$ & $0.21 \pm 0.01$ & $0.19 \pm 0.02$ & $0.15 \pm 0.03$ \\
\hline
\end{tabular}


yeast, and 1.111 is the stoichiometric factor that converts glucan, galactan and mannan to equivalent glucose, galactose and mannose, respectively.

In addition, the volumetric productivity ( $Q_{p}, g$ of ethanol $/(L \cdot h)$ ) is usually an interesting way to select the better operational conditions from a techno-economic point of view, and can be calculated as:

$Q_{P}=\frac{[E t O H]_{t}}{t}$

Where $[\mathrm{EtOH}]_{\mathrm{t}}$ is the ethanol concentration $(\mathrm{g} / \mathrm{L})$ at a time $\mathrm{t}$ (hour).

\section{Results and discussion}

\subsection{Autohydrolysis pretreatment}

Non-isothermal autohydrolysis was chosen as a suitable green pretreatment for Sargassum muticum, where no other compounds but water are added to the raw material, making this pretreatment an environmentally friendly first step of macroalgae processing.

Experiments were carried out in a wide range of mild severities, 1.69-3.06 (corresponding to $\mathrm{T}_{\operatorname{MAX}}$ between 130 and $180^{\circ} \mathrm{C}$ ) to study the whole process, beginning with low severities (with high solid yields but minimum fractionation of the raw material and glucan susceptibility) to high severities (with lower solid yields but great solubilization and higher enzymatic susceptibility of the solid phase). Also, high-solid loadings ( $C=14.3 \mathrm{~kg}$ of solid $/ 100 \mathrm{~kg}$ of total weight) were employed in order to minimize the quantity of water and to make the process more economically viable [34]. In this way, the main aims of this process are the search of: (i) high enzymatic susceptibility of the solid, which allows higher glucose conversion in the enzymatic hydrolysis assays, and hence higher maximum ethanol yields in the fermentation steps, and (ii) high content of hexoses in both liquid and solid phases. It permits to reach higher monomeric concentrations of glucose, galactose and mannose for subsequent fermentation step to produce ethanol.

Table 2 shows the conditions of treatment, solid yield and the composition of the solid and liquid phase of Sm after the nonisothermal autohydrolysis procedure.

The degree of fractionation of the process is measured by the solid yield (SY), which decreases with the severity, from $89.29 \%$ (at lowest severity of $S_{0=1.69)}$ to values of about $65-68 \%$ at severities higher than 2.80 .

In relation to composition of solid phase, the AIR is the major component, increasing its content when severity increases, with a recovery higher than $100 \%$, so it seems that part of the extracts or other components can contribute to this fraction. The second main component was the glucan, that increases its content up to $14.91 \mathrm{~g}$ of glucan/100 g autohydrolyzed $\mathrm{Sm}$, o.d.b. operating at $\mathrm{S}_{0}=2.84$. Almost all the glucan, remained in the solid phase, with recoveries of $95-100 \%$ of initial glucan at severities of $2.34-2.84$. Galactan and manan are polysaccharides composed by hexose units, which decrease their content to values of about $2 \mathrm{~g} / 100 \mathrm{~g}$ autohydrolyzed Sm, o.d.b., with an average recovery of $43 \%$ of initial components. Fucoidan shows a similar behavior than galactan and manan, decreasing the content when the severity increases, with a minimum value of $1.46 \mathrm{~g}$ fucoidan/100 g autohydrolyzed Sm, o.d.b., at $\mathrm{S}_{0}=2.84$. The average recovery was $45 \%$ of initial fucoidan. Xylan was present in minor amounts, with values of $0.88-0.24 \mathrm{~g}$ of xylan/ $100 \mathrm{~g}$ of autohydrolyzed Sm, o.d.b., and a faster solubilization, decreasing the recoveries up to values of less than $10 \%$ of initial xylan at highest severity. In addition, low values of acetyl groups, $0.05-0.13 \mathrm{~g}$ of acetyl groups $/ 100 \mathrm{~g}$ of autohydrolyzed Sm, o.d.b, are found in the solid phase.
Regarding to the composition of liquid phase, the quantity of sugars (oligomers and monomers) in the liquor increased with the severity, finding a maximum value at $\mathrm{S}_{0=} 2.84$ with $20.58 \mathrm{~g}$ oligomers and monomers/L. The minimum value was obtained at lowest severity, with $12.16 \mathrm{~g}$ of oligomers and monomers/L. Concerning glucan derived compounds, small quantities of glucooligosaccharides (GO) and glucose (G) appeared in the liquor (1.04-2.73 $\mathrm{g}$ of $(\mathrm{G}+\mathrm{GO}) / \mathrm{L})$. Thus, maximum of solubilization for the other hexoses (expressed as the sum of galactose, galactooligosaccharides, mannose and mannooligosacharides, $\mathrm{Ga}+\mathrm{GaO}+\mathrm{Ma}+\mathrm{MaO}$ ) reached $4.97 \mathrm{~g} / \mathrm{L}$ (about a $57.88 \%$ of the initial content) in the liquor at $\mathrm{S}_{0=} 2.84$.

The solubilization of $\mathrm{Xn}$ (in form of xylose and xylooligosaccharides, $\mathrm{X}+\mathrm{XO}$ ) increased as the severity raised with values between $11.78 \%$ of initial xylan in form of $\mathrm{X}+\mathrm{XO}(0.32 \mathrm{~g}$ of $\mathrm{X}+\mathrm{XO} /$ $\mathrm{L}$ ) in the liquor from $\mathrm{S}_{0}=1.69$ and almost the $70 \%$ of $\mathrm{X}+\mathrm{XO}$ of initial xylan $(1.86 \mathrm{~g}$ of $\mathrm{X}+\mathrm{XO} / \mathrm{L})$ from $\mathrm{S}_{0}=2.59$. Acetic acid presence in the liquor phase (as $\mathrm{AcH}+\mathrm{AcO}$ ) increases from $60.93 \%$ of initial acetyl groups at the lower severity treatment $\left(S_{0}=1.69\right)$ to almost a $100 \%$ at the higher severity $\left(\mathrm{S}_{0}=3.06\right)$, remaining small amounts in the solid phase. Formic acid getting higher values as the severity increases, until $1.58 \mathrm{~g}$ of Fo/L. Meanwhile, no or very little degradation products (HMF and F) were found.

\subsection{Enzymatic susceptibility}

One of the principal objectives of the pretreatment is to increase the enzymatic susceptibility, so three different types of enzymatic hydrolysis (EH) assays were performed (as described in section 2.4.) employing: (i) raw Sm as substrate mixed with water, (ii) autohydrolyzed Sm and water, (iii) whole slurry. The autohydrolysis of $150{ }^{\circ} \mathrm{C}\left(\mathrm{S}_{0}=2.34\right)$ was selected for this experiments due to: (i) the great quantity of hexoses in the solid and liquid phase, (ii) the relatively low severity of pretreatment, (iii) the high solid yield, above $80 \%$.

The EH was carried out in favorable conditions, employed in order to obtain the maximum values of enzymatic conversion and to achieve a better understanding of the influence of nonisothermal autohydrolysis pretreatment in enzymatic susceptibility. These conditions were: consistency, $C=4.76 \mathrm{~kg}$ of solid $/ 100 \mathrm{~kg}$ of total weight, o.d.b.; enzyme to substrate ratio, $\mathrm{ESR}=20 \mathrm{FPU} / \mathrm{g}$; Cellobiase to Celluclast ratio, CCR $=5$ IU/FPU; Viscozyme to Celluclast ratio, $\mathrm{VCR}=5 \mathrm{U} / \mathrm{FPU}$, temperature, $\mathrm{T}=48.5^{\circ} \mathrm{C} ; \mathrm{pH}, 4.85$; agitation, $150 \mathrm{rpm}$.

Fig. 3 shows the experimental results and the calculated curve of glucose following the Holtzapple equation (see section 2.4.). Low $\mathrm{GC}_{\mathrm{MAX}}$ were obtained for the raw material experiment, reaching a $25 \%$ (corresponding to $1.47 \mathrm{~g}$ glucose $/ \mathrm{L}$ ) which can be explained because the solid is not susceptible to enzymatic hydrolysis. When the pretreatment was carried out, $\mathrm{GC}_{\mathrm{MAX}}$ were 4.1 and 5.7 fold much higher for enzymatic hydrolysis with water and with whole slurry, respectively, than Sm without treatment. $\mathrm{GC}_{\mathrm{MAX}}$ achieves values of $94 \%$ of glucose conversion $(6.01 \mathrm{~g}$ of glucose/L) for autohydrolyzed $\mathrm{Sm}$ at $150{ }^{\circ} \mathrm{C}\left(\mathrm{S}_{0}=2.34\right)$ and water, and $89 \%$ of glucose conversion ( $8.35 \mathrm{~g}$ of glucose/L) for autohydrolyzed $\mathrm{Sm}$ at $150{ }^{\circ} \mathrm{C}\left(\mathrm{S}_{0}=2.34\right)$ and liquor. Besides, it shows a fast saccharification, where $\mathrm{GC}=65 \%$ (from the solid mixed with water) and GC $=54 \%$ (from the whole slurry) are achieved in only $8 \mathrm{~h}$ of EH. As expected, the autohydrolysis treatment causes an increase in the EH susceptibility, and the enzymes employed let to increase the glucose concentration in both solid and liquid phase of autohydrolysis, with almost quantitative glucan to glucose conversion. 


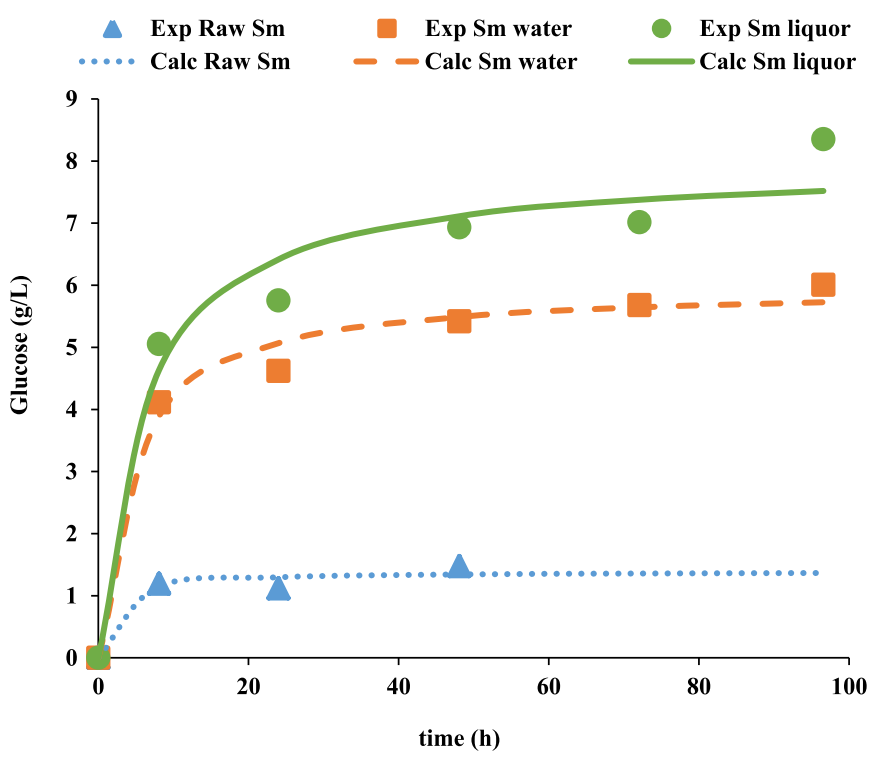

Fig. 3. Enzymatic susceptibility of (i) raw Sm and water, (ii) autohydrolyzed Sm at $150^{\circ} \mathrm{C}$ and water, (iii) whole slurry after non-isothermal autohydrolysis of Sm at $150^{\circ} \mathrm{C}$, represented as calculated from the Holtzapple equation (Calc) and the experimental values (Exp).

\subsection{Simultaneous saccharification and fermentation with different strains of Saccharomyces cerevisiae}

For the SSF stage, two industrial and one laboratory strains of Saccharomyces cerevisiae were selected in order to compare their performance, using the solid phase of the autohydrolysis of $150{ }^{\circ} \mathrm{C}$ $\left(\mathrm{S}_{0}=2.34\right)$ mixed with water at the conditions described in section 2.6.

Fig. 4 shows the time course of ethanol production in the fermentation for the three strains. The three hexoses (glucose, galactose and mannose) are consumed rapidly, allowing to reach maximum possible ethanol concentrations. The maximum ethanol yield for Ethanol Red ${ }^{\circledR}$ was $87.7 \%$ (9.95 g of ethanol/L), while PE2
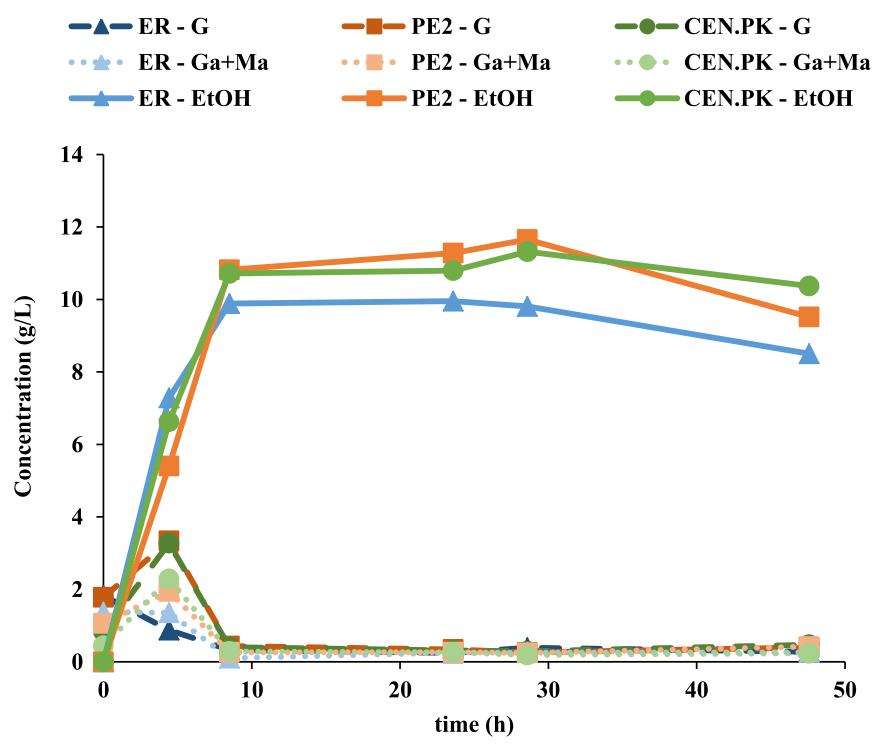

Fig. 4. SSF of the solid phase from autohydrolysis of $150{ }^{\circ} \mathrm{C}\left(\mathrm{S}_{0}=2.34\right)$ (ER (Ethanol Red $\left.{ }^{\circledR}\right)$, PE2 (PE2), CEN.PK (CEN.PK 113-7D), G (Glucose), Ga + Ma (Galactose + Mannose), EtOH (Ethanol)). and the laboratory strain CEN.PK 113-7D were near of 100\% (11.65 and $11.32 \mathrm{~g}$ of ethanol/L, respectively). In only $8.5 \mathrm{~h}$, ethanol yields between 87 and 95\% are achieved, pretty much faster than with other macroalgae and/or pretreatments $[35,36]$. As example, after $8.5 \mathrm{~h}$ of SSF, the yields obtained with the different strains were $87.1 \%$ with Ethanol Red ${ }^{\circledR}$ (instead maximum values of $87.7 \%$ at 23.6 h), 95.3\% with PE2 and 94.4\% with CEN.PK 113-7D (instead $100 \%$ after $28.6 \mathrm{~h}$ ), that means $93-99 \%$ of maximum yield in only $8.5 \mathrm{~h}$.

Although these two latter strains seemed to work well with this substrate and conditions, PE2 was employed for superior capacity to ferment in presence of inhibitors, as shown for the inhibitors derived from hardwood processing as Eucalyptus wood [37].

\subsection{SSF comparing with whole slurry}

For the last step of SSF, it was decided to use de strain PE2 with the solid phase of the autohydrolysis of $150{ }^{\circ} \mathrm{C}\left(\mathrm{S}_{0}=2.34\right)$ mixed with water and liquor at consistencies of 14.3 and $11.1 \mathrm{~kg}$ of solid/ $100 \mathrm{~kg}$ of total weight, o.d.b., with the conditions explained in section 2.6. Table 3, shows the nomenclature of the SSF experiments.

In a similar way to the previous assays, Fig. 5 shows that almost all the glucose, galactose and mannose is consumed before $10 \mathrm{~h}$ of fermentation, increasing the ethanol concentration to values between 10.13 and $12.23 \mathrm{~g}$ of ethanol/L (values corresponding to $68-95 \%$ of maximum ethanol concentrations). This could lead to become an interesting alternative for bioethanol production in industry, reducing times with a quickly fermentation.

Maximum ethanol yields in the range $78 \%-100 \%$ were achieved. The whole slurry assay of $C=11.1 \mathrm{~kg}$ of solid $/ 100 \mathrm{~kg}$ of total weight, o.d.b. reached that $78 \%$ of maximum ethanol yield $(10.72 \mathrm{~g}$ of

Table 3

Nomenclature of the SSF experiments, specifying the liquid phase and the consistencies employed.

\begin{tabular}{lllll}
\hline & SSF 1 & SSF 2 & SSF 3 & SSF 4 \\
\hline Liquid phase & liquor & water & liquor & water \\
C (\%) & 11.1 & 11.1 & 14.3 & 14.3 \\
\hline
\end{tabular}

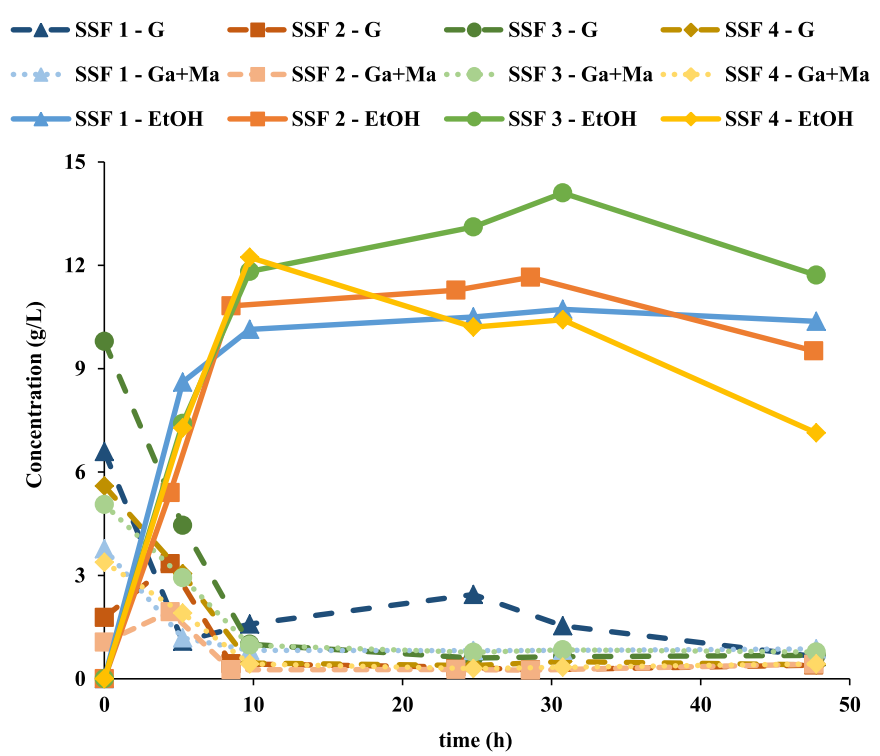

Fig. 5. SSF of the solid phase from autohydrolysis of $150^{\circ} \mathrm{C}\left(\mathrm{S}_{0}=2.34\right) \mathrm{G}$ (Glucose), $\mathrm{Ga}+\mathrm{Ma}$ (Galactose plus Mannose), EtOH (Ethanol). 
ethanol/L), while the mixture with water was the same as in section 3.3 , achieving a yield of $100 \%$. However, and as expected, higher consistencies ( $14.3 \mathrm{~kg}$ of solid/100 kg of total weight) allowed to get higher maximum concentrations of ethanol, of $12.23 \mathrm{~g}$ of ethanol/L using water as liquid phase, and $14.10 \mathrm{~g}$ of ethanol/L using liquor as liquid phase (both with a maximum ethanol yield of $81 \%$ ).

In the experiments carried out at $C=14.3 \mathrm{~kg}$ of solid $/ 100 \mathrm{~kg}$ of total weight, o.d.b., the ethanol yield was slightly higher than in the experiments at $C=11.1 \%$, when the expected behavior would be on the contrary (increasing the $C$ should decrease the ethanol yields). This fact can be due to three possible causes: (i) experimental error could have influenced (although the average standard deviation is about a $4 \%$ and the difference between the two ethanol yields values (78-81\%) was low, only $3 \%$ ), (ii) since the consistencies employed are similar (11.1 and $14.3 \%$ ), this could show that there is no significantly differences in the mass transference in both consistencies or that, at this values of $\mathrm{C}$, there is no limitations in the transport of the components involved, or (iii) the majority of inhibitor compounds are found in the liquor (especially phenolic compounds, [21]), so, although the concentration of inhibitors is the same irrespective of the consistency, the total quantity of inhibitors (per g of Sargassum muticum and per unit of microorganism) may be higher at $\mathrm{C}=11.1 \%$ owing to a higher liquor content at same total volume.

Table 4 shows the volumetric productivity of the SSF assays. Although the high $Q_{p}$ at $t=5 h$, it is important to notice that at $\mathrm{t}=9 \mathrm{~h} \mathrm{Q}_{\mathrm{p}}$ has only decreased slightly but counting almost the double of ethanol concentration in the great majority of assays (and ethanol yields between 68 and 95\%). However, taking into account the time when the ethanol concentration is maximum, only one of them (SSF 4 ) corresponds to $\mathrm{t}=9 \mathrm{~h}$, while the rest of them correspond to $\mathrm{t}=30 \mathrm{~h}$. Bearing this in mind, not only the maximum concentration of ethanol is key in an industrial SSF but the speed with which the ethanol is obtained.

As a conclusion, Sm has some interesting points to be a potential biomass for the production of bioethanol:

1. According to the Spanish Catalog of Invasive Alien Species, $\mathrm{Sm}$ is an invasive macroalgae in Europe and North America (and especially in the NW of Spain), so it is advantageous to find a use for this algae, obtaining a double environmental and economic benefit: the elimination of this problematic material, and the economical revalorization of the algae, that actually are useless and without value.

2. The high protein content of Sm allows to perform the fermentation step without the addition of any nutrient, which means an important decrease in the industrial production cost.

3. It could be used in combination with other biomasses, allowing a faster and higher ethanol production and the avoidance of nutrient addition. In this way, another biomass, for instance a lignocellulosic material (LCM), could be added to the resulting medium of the fermentation of algae, in order to perform a

\section{Table 4}

Volumetric productivity $\left(Q_{p}\right.$, g of ethanol $\left.\cdot \mathrm{L}^{-1} \cdot \mathrm{h}^{-1}\right)$ of the SSF of the solid phase from autohydrolysis of $150^{\circ} \mathrm{C}\left(\mathrm{S}_{0}=2.34\right)$ where $\mathrm{Q}_{\mathrm{P}}, \mathrm{Q}_{\mathrm{P}}, \mathrm{Q}_{\mathrm{P}}{ }_{24}, \mathrm{Q}_{\mathrm{P}}{ }_{30}, \mathrm{Q}_{\mathrm{P}} 48$ represents the volumetric productivity at time around $5,9,24,30$ and $48 \mathrm{~h}$, respectively. The time when the SSF reaches the maximum ethanol concentration are underlined and bold.

\begin{tabular}{|c|c|c|c|c|}
\hline & SSF 1 & SSF 2 & SSF 3 & SSF 4 \\
\hline$Q_{P} 5$ & 1.64 & 1.22 & 1.41 & 1.39 \\
\hline $\mathrm{Q}_{\mathrm{P} 9}$ & 1.04 & 1.27 & 1.21 & $\underline{1.25}$ \\
\hline $\mathrm{Q}_{\mathrm{P} 24}$ & 0.42 & 0.48 & 0.53 & $\overline{0.44}$ \\
\hline $\mathrm{Q}_{\mathrm{P} 30}$ & 0.35 & 0.41 & 0.46 & 0.34 \\
\hline $\mathrm{QP}_{48}$ & $\overline{0.22}$ & $\overline{0.20}$ & $\overline{0.25}$ & 0.15 \\
\hline
\end{tabular}

fermentation of the glucan contained in LCM, highlighting two advantages: (i) increasing the final ethanol concentration employing both seaweed and LCM, and (ii) the probably avoidance of employing nutrients, being a more cost-effective procedure.

4. This work proves the feasibility to successfully obtain ethanol (referred to high ethanol yields and short times of reaction) employing environmentally friendly treatments (using only water as a reagent at low temperatures), conditions which could be extrapolated to another seaweeds with higher polysaccharides content.

\section{Conclusions}

Sargassum muticum is a suitable material for third generation bioethanol production, due to its hexose content (15.29\% of the raw material on a dry basis) and high protein content (10.55\%).

Non-isothermal autohydrolysis is an effective pretreatment to the fractionation of Sargassum muticum. Glucan can be almost totally retained in the solid phase, while other compounds can be almost totally or partially solubilized (as xylan and galactan + mannan, respectively). Optimal conditions lead to high glucose conversions (which means a high enzymatic susceptibility) close to the $100 \%$, with a $50 \%$ conversion in less than $10 \mathrm{~h}$.

The comparison of microorganisms showed up that the industrial strain PE2 is able to work well with Sargassum muticum substrates, reaching high ethanol yields at high speed. Consequently, the SSF experiments carried out at different consistencies (of 11.1 and $14.3 \mathrm{~kg}$ of solid/100 kg of total weight, o.d.b.) and mixing the solid with water or liquor, confirms the suitability of this microorganism. Ethanol yields from $68 \%$ to $100 \%$ are achieved in less than $10 \mathrm{~h}$ with fast kinetics and high values of $\mathrm{Q}_{\mathrm{p}}$, and maximum ethanol concentrations of $10.72-14.10 \mathrm{~g}$ of ethanol/L.

\section{Acknowledgments}

Authors are grateful to spanish Ministry of Economy and Competitiveness (research project "Multistage projects for the integral benefit of macroalgae and vegetable biomass" with reference CTM2015-68503) and to Xunta de Galicia (Galician Competitive Research Group GRC 2017/62 and to the CITACA Strategic Partnership), these three programs partially funded by FEDER of European Union; to the Portuguese Foundation for Science and Technology (reference UID/BIO/04469/2019 unit), and to European Regional Development Fund under the scope of Norte2020 - Programa Operacional Regional do Norte (reference NORTE-01-0145-FEDER000004). Pablo G. del Río is grateful to the Ministry of Education, Culture and Sports of Spain for his FPU research grant.

\section{Appendix A. Supplementary data}

Supplementary data to this article can be found online at https://doi.org/10.1016/j.renene.2019.03.083.

\section{References}

[1] G.S. Hossain, L. Liu, G.D. Du, Industrial bioprocesses and the biorefinery concept, Curr. Dev. Biotechnol. Bioeng. Bioprocess. Bioreact. Controls (2017) 3-27, https://doi.org/10.1016/B978-0-444-63663-8.00001-X.

[2] G. De Bhowmick, A.K. Sarmah, R. Sen, Lignocellulosic biorefinery as a model for sustainable development of biofuels and value added products, Bioresour. Technol. 247 (2018)1144-1154, https://doi.org/10.1016/j.biortech.2017.09.163.

[3] R. Nisticò, Aquatic-derived biomaterials for a sustainable future: a European opportunity, Resources 6 (2017) 65, https://doi.org/10.3390/resources6040065.

[4] E.T. Kostas, D.A. White, D.J. Cook, Development of a bio-refinery process for the production of speciality chemical, biofuel and bioactive compounds from Laminaria digitata, Algal Res. 28 (2017) 211-219, https://doi.org/10.1016/ 
j.algal.2017.10.022.

[5] R. Jiang, K.N. Ingle, A. Golberg, Macroalgae (seaweed) for liquid transportation biofuel production: what is next? Algal Res. 14 (2016) 48-57, https://doi.org/ 10.1016/j.algal.2016.01.001.

[6] L. Pérez, E. Conde, H. Domínguez, Microwave hydrodiffusion and gravity of Sargassum muticum, Process Biochem. 49 (2014) 981-988, https://doi.org/ 10.1016/j.procbio.2014.02.020.

[7] P. Pérez-López, E.M. Balboa, S. García-González, H. Domínguez, G. Feijóo, M.T. Moreira, Comparative environmental assessment of valorization strategies of the invasive macroalgae Sargassum muticum, Bioresour. Technol. 161 (2014) 137-148, https://doi.org/10.1016/j.biortech.2014.03.013.

[8] E.M. Balboa, C. Gallego-Fábrega, A. Moure, H. Domínguez, Study of the seasonal variation on proximate composition of oven-dried Sargassum muticum biomass collected in Vigo Ria, Spain, J. Appl. Phycol. 28 (2016) 1943-1953, https://doi.org/10.1007/s10811-015-0727-x.

[9] A. Tanniou, L. Vandanjon, M. Incera, E. Serrano Leon, V. Husa, J. Le Grand, J.L. Nicolas, N. Poupart, N. Kervarec, A. Engelen, R. Walsh, F. Guerard, N. Bourgougnon, V. Stiger-Pouvreau, Assessment of the spatial variability of phenolic contents and associated bioactivities in the invasive alga Sargassum muticum sampled along its European range from Norway to Portugal, J. Appl. Phycol. 26 (2014) 1215-1230, https://doi.org/10.1007/s10811-013-0198-X.

[10] J.-H. Yeon, S.-E. Lee, W.Y. Choi, D.H. Kang, H.-Y. Lee, K.-H. Jung, Repeatedbatch operation of surface-aerated fermentor for bioethanol production from the hydrolysate of seaweed Sargassum sagamianum, J. Microbiol. Biotechnol. 21 (2011) 323-331, https://doi.org/10.4014/jmb.1010.10057.

[11] M.G. Borines, R.L. de Leon, J.L. Cuello, Biethanol production from the macroalgae Sargassum spp, Bioresour. Technol. 138 (2013) 22-29, https://doi.org 10.1016/j.biortech.2013.03.108.

[12] T. Widyaningrum, I. Prastowo, M. Parahadi, A.D. Prasetyo, Production of bioethanol from the hydrolysate of Brown seaweed (Sargassum crassifolium) using a naturally $\beta$-glucosidase producing yeast Saccharomyces cerevisiae JCM 3012, Biosci. Biotechnol. Res. Asia 13 (2016) 1333-1340, https://doi.org/ $10.13005 /$ bbra/2274.

[13] C.M.T. Perez, I.G. Pajares, V.A. Alcantara, J.F. Simbahan, Bacterial laminarinase for application in ethanol production from brown algae Sargassum sp. using halotolerant yeast, Biofuel Res. J. 17 (2018) 792-797, https://doi.org/ 10.18331/BRJ2018.5.1.6.

[14] F. Vargas, E. Domínguez, C. Vila, A. Rodríguez, G. Garrote, Biorefinery scheme for residual biomass using autohydrolysis and organosolv stages for oligomers and bioethanol production, Energy Fuels 30 (2016) 8236-8245, https:/ doi.org/10.1021/acs.energyfuels.6b00277.

[15] M.M. Khatun, C.-G. Liu, X.-Q. Zhao, W.-J. Yuan, F.-W. Bai, Consolidated ethanol production from Jerusalem artichoke tubers at elevated temperature by Saccharomyces cerevisiae engineered with inulinase expression through cell surface display, J. Ind. Microbiol. Biotechnol. 44 (2017) 295-301, https:/| doi.org/10.1007/s10295-016-1881-0.

[16] Y.-J. Li, Y.-Y. Lu, Z.-J. Zhang, S. Mei, T.-W. Tan, L.-H. Fan, Co-fermentation of cellulose and sucrose/xylose by engineered yeast for bioethanol production, Energy Fuels 31 (2017) 4061-4067, https://doi.org/10.1021/ acs.energyfuels.7b00032.

[17] S.H. Mohd Azhar, R. Abdulla, Bioethanol production from galactose by immobilized wild-type Saccharomyces cerevisiae, Biocatal. Agric. Biotechnol. 14 (2018) 457-465, https://doi.org/10.1016/j.bcab.2018.04.013.

[18] Y.H. Jung, I.J. Kim, H.K. Kim, K.H. Kim, Dilute acid pretreatment of lignocellulose for whole slurry ethanol fermentation, Bioresour. Technol. 132 (2013) 109-114, https://doi.org/10.1016/j.biortech.2012.12.151.

[19] Y.-G. Lee, Y.-S. Jin, Y.-L. Cha, J.-H. Seo, Bioethanol production from cellulosic hydrolysates by engineered industrial Saccharomyces cerevisiae, Bioresour. Technol. 228 (2017) 355-361, https://doi.org/10.1016/j.biortech.2016.12.042.

[20] H. Chen, X. Fu, Industrial technologies for bioethanol production from lignocellulosic biomass, Renew. Sustain. Energy Rev. 57 (2016) 468-478, https:/ doi.org/10.1016/j.rser.2015.12.069.

[21] N. Flórez-Fernández, M.J. González-Muñoz, H. Domínguez, Feasibility of posthydrolysis processing of hydrothermal extracts from Sargassum muticum, Algal Res. 27 (2017) 73-81. https://doi.org/10.1016/j.algal.2017.08.002.

[22] R. Mittal, H.A. Tavanandi, V.A. Mantri, K.S.M.S. Raghavarao, Ultrasound assisted methods for enhanced extraction of phycobiliproteins from marine macro-algae, Gelidium pusillum (Rhodophyta), Ultrason. Sonochem. 38 (2017) 92-103. https://doi.org/10.1016/j.ultsonch.2017.02.030.

[23] H.-S. Jeong, S.-K. Jang, H.-Y. Kim, H. Yeo, J.W. Choi, I.-G. Choi, Effect of freeze storage on hemicellulose degradation and enzymatic hydrolysis by dilute-acid pretreatment of Mongolian oak, Fuel 165 (2016) 145-151. https://doi.org/10. 1016/j.fuel.2015.10.058.

[24] A. Sluiter, R. Ruiz, C. Scarlata, J. Sluiter, D. Templeton, Determination of Extractives in Biomass, NREL chemical analysis and testing laboratory analytical procedures, 2008. NREL/TP-510-42619.

[25] A. Sluiter, B. Hames, D. Hyman, C. Payne, R. Ruiz, C. Scarlata, J. Sluiter, D. Templeton, J. Wolfe, Determination of Total Solids in Biomass and Total Dissolved Solids in Liquid Process Samples, NREL chemical analysis and testing laboratory analytical procedures, 2008. NREL/TP-510-42621.

[26] A. Sluiter, B. Hames, R. Ruiz, C. Scarlata, J. Sluiter, D. Templeton, Determination of Ash in Biomass, NREL chemical analysis and testing laboratory analytical procedures, 2008. NREL/TP-510-42622.

[27] A. Sluiter, B. Hames, R. Ruiz, C. Scarlata, J. Sluiter, D. Templeton, D. Crocker, Determination of Structural Carbohydrates and Lignin in Biomass, NREL chemical analysis and testing laboratory analytical procedures, 2008. NREL/ TP-510-42618.

[28] N. Blumenkrantz, G. Asboe-Hansen, New method for quantitative determination of uronic acids, Anal. Biochem. 54 (1973) 484-489, https://doi.org/ 10.1016/0003-2697(73)90377-1.

[29] J.M. Lavoie, E. Capek-Menard, H. Chornet, Production of pulp from salix viminalis energy crops using the FIRSST process, Bioresour. Technol. 101 (2010) 4940-4946, https://doi.org/10.1016/j.biortech.2009.09.021.

[30] T.K. Ghose, Measurement of cellulase activities, Pure Appl. Chem. 59 (1987) 257-268, https://doi.org/10.1351/pac198759020257.

[31] M. Paquot, P. Thonart, Hydrolyse enzymatique de la cellulose régénérée, Holzforschung 36 (1982) 177-181, https://doi.org/10.1515/ hfsg.1982.36.4.177.

[32] I.Y. Sunwoo, J.E. Kwon, T.H. Nguyen, C.H. Ra, G.-T. Jeong, S.-K. Kim, Bioethanol production using waste seaweed obtained from Gwangalli Beach, Busan, Korea by Co-culture of yeasts with adaptive evolution, Appl. Biochem. Biotechnol. 183 (2017) 966-979, https://doi.org/10.1007/s12010-017-2476-6.

[33] M.T. Holtzapple, H.S. Caram, A.E. Humphrey, Comparison of two empirical models for the enzymatic hydrolysis of pretreated poplar wood, Biotechnol. Bioeng. 26 (1984) 936-941, https://doi.org/10.1002/bit.260260818.

[34] D.L. Aguilar, R.M. Rodríguez-Jasso, E. Zanuso, D.J. de Rodríguez, L. AmayaDelgado, A. Sánchez, H.A. Ruiz, Scale-up and evaluation of hydrothermal pretreatment in isothermal and non-isothermal regimen for bioethanol production using agave bagasse, Bioresour. Technol. 263 (2018) 112-119, https:// doi.org/10.1016/j.biortech.2018.04.100.

[35] T.H. Nguyen, C.H. Ra, I.Y. Sunwoo, G. Jeong, S. Kim, Bioethanol production from Gracilaria verrucosa using Saccharomyces cerevisiae adapted to $\mathrm{NaCl}$ or galactose, Bioproc. Biosyst. Eng. 40 (2017) 529-536, https://doi.org/10.1007/ s00449-016-1718-2.

[36] R.M. Soliman, S.A. Younis, N.Sh. El-Gendy, S.S.M. Mostafa, S.A. El-Temtamy, A.I. Hashim, Batch bioethanol production via the biological and chemical saccharification of some Egyptian marine macroalgae, J. Appl. Microbiol. (2018), https://doi.org/10.1111/jam.13886.

[37] F.B. Pereira, A. Romaní, H.A. Ruiz, J.A. Teixeira, L. Domingues, Industrial robust yeast isolates with great potential for fermentation of lignocellulosic biomass, Bioresour. Technol. 161 (2014) 192-199, https://doi.org/10.1016/ j.biortech.2014.03.043. 